\title{
QTAIM-DI-VISAB computational study on the so-called nonclassical bicyclobutonium cation
}

\author{
Nick H. Werstiuk, ${ }^{a}{ }^{*}$ Daniel A. Poulsen ${ }^{b}$ \\ ${ }^{a}$ Department of Chemistry, McMaster University Hamilton, ON L8S 4M1, Canada \\ ${ }^{b}$ Department of Chemistry, University of California Berkeley, CA 94720-1460 \\ E-mail: werstiuk@mcmaster.ca
}

\begin{abstract}
This paper is dedicated to Ted Sorensen for his contributions to chemistry on the occasion of his $75^{\text {th }}$ birthday
\end{abstract}

\begin{abstract}
QTAIM-DI-VISAB analyses at the CCSD and B3PW91 levels were used to characterize the bonding of the cyclopropylcarbinyl (1) and the so-called 'nonclassical' bicyclobutonium and 1methylbicyclobutonium cations, $\mathbf{2}$ and $\mathbf{3}$ as well as the transition state for rearrangement of $\mathbf{1}$ to 2. These analyses involved obtaining QTAIM molecular graphs and delocalization indexes (DIs) for pairs of atoms that were correlated with the proximities of atomic basins (VISAB). This study showed that the supposed nonclassical bicyclobutonium and 1-methylbicyclobutonium cations do not exhibit penta-coordinate carbons at their equilibrium geometries as has been claimed. Both species are best described as distorted cyclobutyl cations that exhibit a single ring critical point in the topology of the charge density.
\end{abstract}

Keywords: Cyclopropylcarbinyl cation, bicyclobutonium cation, 1-methybicyclobutonium cation, DFT, MP2 and CCSD calculations, QTAIM-DI-VISAB analysis, molecular structure

\section{Introduction}

The cyclopropylcarbinyl cation (1) and its isomer, the so-called nonclassical bicyclobutonium cation (2) as well as its 1-methyl analogue (3) whose structures are shown using the usual dashed-line formalism have been the focus of numerous experimental and computational studies over the span of several decades with the latest being the work of Olah and coworkers. ${ }^{1}$ The dashed-line structures of $\mathbf{2}$ and $\mathbf{3}$ have gradually been replaced with ORTEP-type/solid-line structures, shown as 4 , the implication being that $\mathrm{C} 3$ is a penta-coordinate atom in both representations. 


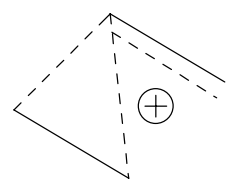

1

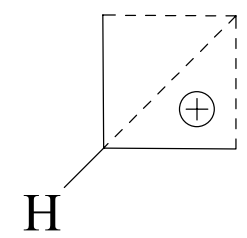

2

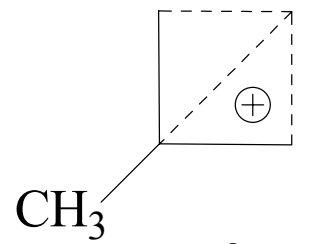

3

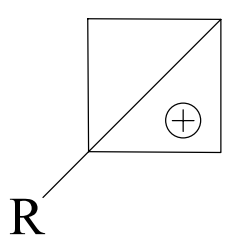

4

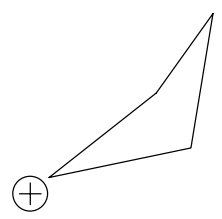

5

Numerous computational studies have been carried out over the space of two decades ranging from MINDO/ $3^{2}$ to MP4(SDTQ)/MP2//MP2/6-31G(d,p) $+\mathrm{ZPE}^{3}$ and MP4(SDTQ)/ccpVTZ//MP2/cc-pVTZ + ZPE levels ${ }^{1}$. Computational studies were also carried out in solvent fields. ${ }^{4}$ The main focus of the most recent study on $\mathbf{2}$ and $\mathbf{3}$ carried out by Olah et al. at various levels, including MP4(SDTQ)/cc-pVTZ//MP2/cc-pVTZ + ZPE was the calculation of ${ }^{13} \mathrm{C}$ NMR chemical shifts at $\operatorname{CCSD}(\mathrm{T}) .{ }^{1}$ With the exception of Brown's proposal ${ }^{5}$ based on solvolysis data the cation should be viewed as a distorted cyclobutyl cation represented as $\mathbf{5}$, dashed-line or solid-line structures have been used to represent the bonding of these alleged nonclassical pentacoordinate species in all the studies carried out to this point.

Our recent computational studies on a number of cations, including 2-norbornyl, established that coordination based on the number of bond paths - as defined in a QTAIM ${ }^{6}$ molecular graph - terminating at a nucleus in any species - cation, carbanion, radical, or carbene - should be used as the criterion of hyper-coordination and hyper-valency. ${ }^{7,8,9,10}$ A QTAIM treatment precludes interpretational bias of the nature of bonding based on qualitative evidence such as interatomic distances. We argued that this approach should be used regardless of the nature of the intermediate to obviate the confusion and inaccuracies associated with arbitrarily using indicators such as dashed lines, dotted lines, cross-hatched lines, hollow tubes, and solid tubes in structural formulas. In addition to using QTAIM molecular graphs that unambiguously define molecular structure, we recently showed that QTAIM-DI-VISAB analyses are useful for characterizing the bonding in molecules at their equilibrium geometries and refining our knowledge of the bonding in hyper-coordinated species. ${ }^{11,12,13,14}$ In addition to obtaining molecular graphs, delocalization indexes (DIs) are used to establish the importance of delocalization between pairs of atoms that are correlated with the proximity of atomic basins as visualized in displays of these basins (VISAB). This paper reports the results of a QTAIM-DIVISAB study on $\mathbf{1}, \mathbf{2}$, and $\mathbf{3}$, the goal being to establish whether $\mathbf{2}$ and $\mathbf{3}$ are pentacoordinate species as has been claimed. 


\section{Computational methods}

Our previous experiences with DFT calculations on carbocations clearly showed that the B3PW91 hybrid functional is superior to B3LYP in computing the geometries of delocalized, socalled nonclassical species. ${ }^{7,8,9,10}$ We obtained additional support for this finding by carrying out calculations on O-protonated 2,2-dimethyloxirane - studied by Carlier et al. ${ }^{15}$ and described as a particularly challenging computational problem - to compare results from B3LYP, B3PW91, PBE1PBE, and CCSD calculations at the 6-311G(d,p) level as implemented in G03. ${ }^{16}$ The results presented in an earlier publication ${ }^{13}$ clearly established that B3PW91 and PBE1PBE are expected to be superior to B3LYP for obtaining equilibrium geometries in cases where relatively weak polar bonds are involved. In this study, cation geometries were optimized at B3PW91 and MP2 levels with a range of basis sets - 6-311+G(2d,p), cc-pVTZ, and aug-cc-pVTZ with OPT=TIGHT and OPT=VERYTIGHT and wave functions obtained. The OPT=VERYTIGHT B3PW91 calculations on 2 were carried out with INT=ULTRAFINE. On the other hand, $\mathrm{CCSD}$ (full) calculations with OPT=TIGHT were carried out first with $6-31+\mathrm{G}(\mathrm{d}, \mathrm{p})$ and then with the $6-311+G(2 d, p)$ basis set. It should be pointed out that while MP2(frozen core) geometry optimizations with the cc-pVTZ - as reported by Olah et al. ${ }^{1}$ - and aug-cc-pVTZ basis sets converged, this was not the case at MP2(full); we found that none of the cc-pVTZ and aug-ccpVTZ MP2(full) calculations converged. Consequently, the MP2 calculations were discounted and not used in this study. Moreover, it appears that MP2 often tends to overestimate the stability of 'nonclassical' structures. ${ }^{17}$ While $\mathbf{1}$ and $\mathbf{2}$ were viewed as unsymmetrical species by Casanova et al. ${ }^{4}$, we found that OPT=TIGHT calculations yielded geometries that were extremely close to the $C_{S}$ structures. Consequently we fixed the symmetry - in our case using Chemcraft ${ }^{18}-$ to $C_{S}$ as did Olah et al. ${ }^{1}$

Selected inter-nuclear distances of $\mathbf{1 -} C_{S}, \mathbf{2}-C_{S}$, and $\mathbf{3}-C_{S}$ obtained at $\operatorname{CCSD}($ full)/6$311+\mathrm{G}(2 \mathrm{~d}, \mathrm{p})$ with OPT=TIGHT are displayed as Figure 1(a), (c), and (d), respectively. Frequency calculations were carried out on the stationary points to confirm them as energy minima or transitions states. B3PW91 and CCSD energies and thermochemical data are collected in Table 1. QTAIM analyses of the wave functions to investigate the topologies of the electron densities were carried out with AIM $2000^{19}$ and the obtained molecular graphs are shown in Figure 2 to 4 . AIMALL_ $08^{20}$ was used to integrate atomic basins, obtain atomic populations, calculate total charges as well as atomic overlap matrices required for DI calculations. Values of $\rho\left(\mathbf{r}_{\mathrm{c}}\right)$ at selected bond critical points are collected in Table 2. That the total charges of the cations obtained at the various levels of theory differed by less than $1 \%$ from the expected value of 1.0 confirmed the quality and validity of the QTAIM data (Table 3). This conclusion was supported by the fact that $\mathrm{E}_{\text {elec }}(\Sigma \mathrm{E}(\Omega))$, the sum of the atom energies $\mathrm{E}(\Omega)$ obtained with AIMALL for $\mathbf{1}$, TS-1 $\rightarrow \mathbf{2}, \mathbf{2}$, and $\mathbf{3}$ differed from the G03 molecular energy $\mathrm{E}_{\text {elec }}$ (Table 3) by less than $0.45 \mathrm{kcal} \mathrm{mol}^{-1}$. The program LI-DICALC ${ }^{21,22,23}$ was used to obtain DIs; selected values for pairs of atoms are collected in Table 4. Isosurface plots of the density of atomic basins (Figure 5 Figure 8) were obtained with AIM 2000 at a contour value of 0.005 which includes $>95 \%$ of the electrons using a mesh grid size of 0.125 and plotted with a sphere size of 0.15 . 


\section{Results and Discussion}

\section{Thermochemistry}

Table 1. Total and relative energies of cations at B3PW91/aug-cc-pVTZ(tight) and $\operatorname{CCSD}($ full $) / 6-311+\mathrm{G}(2 \mathrm{~d}, \mathrm{p})$ (tight)

\begin{tabular}{ccccc}
\hline Cation & $\mathbf{1 - C} \boldsymbol{S}$ & $\mathbf{T S}-\mathbf{1} \rightarrow \mathbf{2}$ & $\mathbf{2 -} \boldsymbol{C}_{\boldsymbol{S}}$ & $\mathbf{3 - \boldsymbol { C } _ { \boldsymbol { S } }}$ \\
\hline $\mathrm{E}_{\text {elec }}{ }^{\mathrm{a}}$ & -156.290401 & $-156.289613(+0.48)^{\mathrm{h}}$ & $-156.291993(1.00)^{\mathrm{h}}$ & -195.624835 \\
& & $\left(-136.8 \mathrm{~cm}^{-1}\right)^{\mathrm{i}}$ & & \\
$E_{\text {elec }}{ }^{\mathrm{b}}$ & & & -155.291993 & \\
$\mathbf{E}_{\mathbf{e l e c}}{ }^{\mathrm{c}}(\mathrm{CCSD})$ & $\mathbf{- 1 5 5 . 9 7 3 4 5 8}$ & - & $\mathbf{- 1 5 5 . 9 7 3 1 7 0}(+\mathbf{0 . 1 8})$ & $\mathbf{- 1 9 5 . 2 2 7 5 1 4}$ \\
$\mathrm{E}_{0}{ }^{\mathrm{d}}$ & -156.193468 & $-156.192121(+1.09)$ & $-156.193856(-0.24)$ & -195.499150 \\
$\mathrm{E}_{298}{ }^{\mathrm{e}}$ & -156.188554 & -156.188239 & -156.189409 & -195.493515 \\
$\mathrm{H}_{298}{ }^{\mathrm{f}}$ & -156.187609 & $-156.187296(+1.96)$ & $-156.188460(-0.54)$ & -195.492571 \\
$\mathrm{G}_{298}{ }^{\mathrm{g}}$ & -156.220706 & $-156.217907(+1.76)$ & $-156.220120(+0.37)$ & -195.527173 \\
\hline
\end{tabular}

${ }^{\mathrm{a}} \mathrm{E}_{\text {elec }}$ is the uncorrected total energy in hartrees. ${ }^{\mathrm{b}} E_{\text {elec }}$ is the uncorrected total energy in hartrees at B3PW91/aug-cc-pVTZ(opt=verytight, int=ultrafine). ${ }^{\mathrm{c}} \mathbf{E}_{\text {elec }}$ in bold is the uncorrected $\operatorname{CCSD}\left(\right.$ full)/6-311+G(2d,p)(tight) total energy in hartrees. ${ }^{\mathrm{d}} \mathrm{E}_{0}=\mathrm{E}_{\text {elec }}+\mathrm{ZPE} \quad{ }^{\mathrm{e}} \mathrm{E}=\mathrm{E}_{0}+\mathrm{E}_{\mathrm{vib}}+$ $\mathrm{E}_{\text {rot }}+\mathrm{E}_{\text {trans. }}{ }^{\mathrm{f}} \mathrm{H}=\mathrm{E}+\mathrm{RT} .{ }^{\mathrm{g}} \mathrm{G}=\mathrm{H}+\mathrm{S}$. ${ }^{\mathrm{h}}$ Values in brackets relative to $\mathbf{1 -} \boldsymbol{C}_{\boldsymbol{S}}$ in $\mathrm{kcal} \mathrm{mol}^{-1}$. ${ }^{\mathrm{i}}$ The imaginary frequency.

Selected thermochemical data for $\mathbf{1 -} \boldsymbol{C}_{\boldsymbol{S}}$, TS-1 $\rightarrow \mathbf{2}, \mathbf{2 -} \boldsymbol{C}_{\boldsymbol{S}}$, and 3- $\boldsymbol{C}_{\boldsymbol{S}}$ are collected in Table 1 . As was found previously ${ }^{1}$ cations $\mathbf{1 -} \boldsymbol{C}_{\boldsymbol{S}}$, and $\mathbf{2 - C _ { S }}$ are very close in energy: at B3PW91/aug-ccpVTZ, 2- $\boldsymbol{C}_{\boldsymbol{S}}$ is lower in energy than $\mathbf{1 -} \boldsymbol{C}_{\boldsymbol{S}}$ based on the ZPE-corrected difference in energy $\Delta \mathrm{E}_{0}(-$ $\left.0.24 \mathrm{kcal} \mathrm{mol}^{-1}\right)$ and $\Delta \mathrm{H}_{298}\left(-0.54 \mathrm{kcal} \mathrm{mol}^{-1}\right)$. On the other hand 1- $\boldsymbol{C}_{\boldsymbol{S}}$ was found to be lower in energy than $2-C_{S}$ based on $\Delta \mathrm{G}_{298}\left(+0.37 \mathrm{kcal} \mathrm{mol}^{-1}\right)$ at B3PW91/aug-cc-pVTZ(tight) and $\Delta \mathrm{E}_{\text {elec }}$ $\left(+0.18 \mathrm{kcal} \mathrm{mol}^{-1}\right)$ at $\mathrm{CCSD}($ full $) / 6-311+\mathrm{G}(2 \mathrm{~d}, \mathrm{p})(\mathrm{tight})$. As mentioned in the computational methods section we chose to discount MP2 calculations because the optimizations did not converge at the MP2(full)/cc-pVTZ or MP2(full)/aug-cc-pVTZ levels. Given the expected prohibitive length of $\operatorname{CCSD}($ full $) / 6-311+\mathrm{G}(2 \mathrm{~d}, \mathrm{p})$ transition state and frequency calculations we studied TS-1 $\rightarrow \mathbf{2}$ only at the B3PW91/aug-cc-pVTZ(tight) level. As seen in the data collected in Table 1, the vales for $\Delta \mathrm{E}^{\ddagger}$ elec, $\Delta \mathrm{E}^{\ddagger}, \Delta \mathrm{H}^{\ddagger}{ }_{298}$, and $\Delta \mathrm{G}^{\ddagger}{ }_{298}$ for the rearrangement of $\mathbf{1}-\boldsymbol{C}_{\boldsymbol{S}}$ are +0.48 , $+1.09,+1.96$, and $+1.76 \mathrm{kcal} \mathrm{mol}^{-1}$, respectively, consistent with the fact that values ranging from 0.60 to $2.2 \mathrm{kcal} \mathrm{mol}^{-1}$ - uncorrected and ZPE corrected - reported by Olah et al. at various high levels of theory. ${ }^{1}$

\section{Equilibrium geometrical and molecular structures}

Selected equilibrium internuclear distances of $\mathbf{1 -} C_{S}, \mathbf{T S}-\mathbf{1} \rightarrow \mathbf{2}, \mathbf{2 -} \boldsymbol{C}_{\boldsymbol{S}}$, and $\mathbf{3 -} \boldsymbol{C}_{\boldsymbol{S}}$ are collected in Figure 1. 


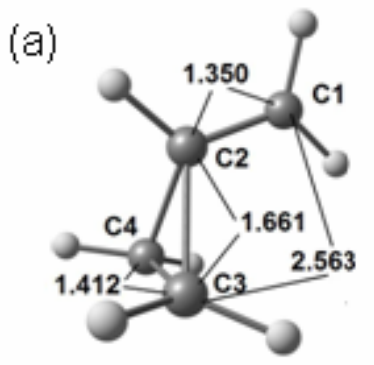

$1-\mathrm{C}_{\mathrm{s}}$ (b)

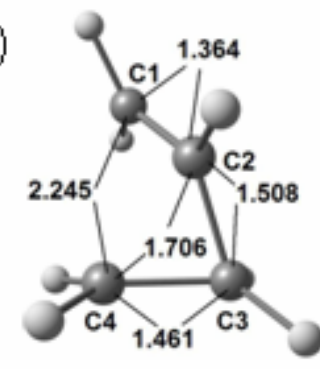

TS- $1 \rightarrow 2$

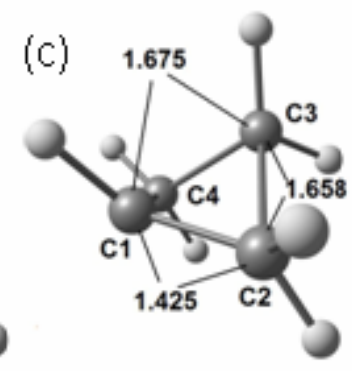

$2-\mathrm{C}_{\mathrm{s}}$

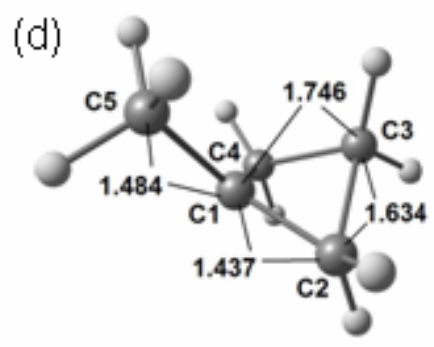

3- $\mathrm{C}_{\mathrm{s}}$

Figure 1. (a) selected internuclear distances $(\AA)$ of $\mathbf{1 -} \boldsymbol{C}_{\boldsymbol{S}}$ at $\operatorname{CCSD}($ full)/6-311+G(2d,p)(tight), (b) TS-1 $\rightarrow$ 2 at B3PW91/aug-cc-pVTZ(tight), (c) $\mathbf{2}-\boldsymbol{C}_{\boldsymbol{S}}$ at $\operatorname{CCSD}$ (full)/6-311+G(2d,p)(tight), and (d) 3- $\boldsymbol{C}_{\boldsymbol{S}}$ at $\mathrm{CCSD}($ full $) / 6311+\mathrm{G}(2 \mathrm{~d}, \mathrm{p})($ tight $)$.

The data obtained at B3PW91/aug-cc-pVTZ differed somewhat from the CCSD(full)/6$311+\mathrm{G}(2 \mathrm{~d}, \mathrm{p})$ values. For example the crucial $\mathrm{C} 1-\mathrm{C} 3$ distances of $\mathbf{2}$ and $\mathbf{3}$ are 1.651 and $1.745 \AA$, respectively, at B3PW91/aug-cc-pVTZ compared to 1.675 and $1.746 \AA$ as shown in Figure 1, suggesting that like MP2 - Olah et al. reported values of 1.648 and $1.698 \AA$ for the C1-C3 distances of $\mathbf{2}-\boldsymbol{C}_{\boldsymbol{S}}$ and $\mathbf{3}-\boldsymbol{C}_{\boldsymbol{S}}$ at MP2(fc)/cc-pVTZ ${ }^{1}-\mathrm{B} 3 \mathrm{PW} 91$ overestimates the delocalization between $\mathrm{C} 1$ and $\mathrm{C} 3$ of $\mathbf{2}-\boldsymbol{C}_{\boldsymbol{S}}$ and $\mathbf{3 -} \boldsymbol{C}_{\boldsymbol{S}}$ somewhat. Even at B3PW91/aug-cc-pVTZ with $\mathrm{opt}=$ verytight and $\mathrm{int}=$ ultrafine the distances the $\mathrm{C} 1-\mathrm{C} 3$ distance of $\mathbf{2}-\boldsymbol{C}_{\boldsymbol{S}}$ is $1.651 \AA$. Olah et al. reported values of 1.717 and $2.446 \AA$ for the $\mathrm{C} 1-\mathrm{C} 4$ and $\mathrm{C} 2-\mathrm{C} 4$ distances of TS-1 $\rightarrow \mathbf{2}$ at MP2(fc)/cc-pVTZ ${ }^{1}$ compared to $1.706 \AA$ and $2.245 \AA$ as shown in Figure 1.

Table 2. Selected QTAIM data for cations at $\operatorname{CCSD}($ full) $/ 6-311+\mathrm{G}(2 \mathrm{~d}, \mathrm{p})($ tight $)$ and B3PW91/aug-cc-pVTZ(tight)

\begin{tabular}{|c|c|c|c|c|c|c|c|c|}
\hline \multirow[t]{2}{*}{ Cation } & \multicolumn{7}{|c|}{$\rho(\mathbf{r}) \mathrm{BCP}$} & \multirow[t]{2}{*}{$\rho(\mathbf{r}) \underline{\mathrm{RCP}}$} \\
\hline & $\mathrm{C} 1-\mathrm{C} 2$ & $\mathrm{C} 2-\mathrm{C} 3$ & C1-C3 & $\mathrm{C} 1-\mathrm{C} 4$ & $\mathrm{C} 2-\mathrm{C} 4$ & $\mathrm{C} 3-\mathrm{C} 4$ & $\mathrm{C} 1-\mathrm{C} 5$ & \\
\hline \multirow[t]{2}{*}{$1-C_{S}$} & $0.3435^{\mathrm{a}}$ & 0.1656 & - & - & $-d$ & 0.2959 & - & 0.1631 \\
\hline & $(0.3515)^{\mathrm{b}}$ & $(0.1759)$ & & & & $(0.3515)$ & & $(0.1737)^{\mathrm{b}}$ \\
\hline \multirow[t]{3}{*}{ TS-1 $\rightarrow 2$} & $(0.3407)$ & $(0.2402)$ & - & $N O$ & $N O$ & (0.2709) & - & $N O R C P$ \\
\hline & & & & $B C P$ & $B C P$ & & & \\
\hline & 0.2878 & 0.1753 & NO BCP & $-{ }^{d}$ & - & $-{ }^{d}$ & - & 0.1571 \\
\hline \multirow[t]{2}{*}{$2-C_{S}$} & $(0.2954)$ & $(0.1815)$ & $N O B C P$ & & & & & $(0.1618)$ \\
\hline & $(0.2954)^{\mathrm{c}}$ & $(0.1815)$ & NO BCP & & & & & $(0.1618)$ \\
\hline \multirow[t]{2}{*}{$3-C_{S}$} & 0.2841 & 0.1843 & NO BCP & $-{ }^{\mathrm{d}}$ & - & $-{ }^{d}$ & 0.2627 & 0.1338 \\
\hline & $(0.2901)$ & (0.1929) & $N O B C P$ & & & & $(0.2736)$ & $(0.1379)$ \\
\hline
\end{tabular}

${ }^{\text {a }}$ At $\operatorname{CCSD}($ full $) / 6-311+\mathrm{G}(2 \mathrm{~d}, \mathrm{p})($ tight $) .{ }^{\mathrm{b}}$ Values in italics in brackets at B3PW91/aug-ccpVTZ(tight). ${ }^{\mathrm{c}}$ Values in bold italics in brackets at B3PW91/aug-cc-pVTZ(opt=verytight, 
int $=$ ultrafine). ${ }^{\mathrm{d}}$ Data for atom pairs related by symmetry not included.

Of importance is the fact that the $\mathrm{C} 1-\mathrm{C} 3$ distance of $\mathbf{3}$ is $0.071 \AA$ greater than the $\mathrm{C} 1-\mathrm{C} 3$ distance of 2 at CCSD(full)/6-311+G(2d,p). Selected QTAIM data for cations at CCSD(full)/6$311+\mathrm{G}(2 \mathrm{~d}, \mathrm{p})($ tight $)$ and B3PW91/aug-cc-pVTZ(tight) are collected in Table 2. The molecular graph of 1 obtained at $\operatorname{CCSD}($ full $) / 6-311+\mathrm{G}(2 \mathrm{~d}, \mathrm{p})($ tight $)$ is displayed as Figure 2(a). The Poincaré-Hopf relationship (NumNACP + NumNNACP - NumBCP + NumRCP - NumCCP = 1) is satisfied. The $\mathrm{C} 2-\mathrm{C} 3$ and $\mathrm{C} 2-\mathrm{C} 4$ bond paths (BPs) are highly curved and the BCPs are in close proximity to the RCP; this means that rearrangement to another molecular structure by coalescence of a BCP and the RCP, as for example through TS-1 $\rightarrow \mathbf{2}$, would require small nuclear displacements and a small activation energy in keeping with the very low barrier calculated for the rearrangement of $\mathbf{1}$ to $\mathbf{2}$. Its molecular structure does not exhibit BCPs between $\mathrm{C} 1 \mid \mathrm{C} 4$ nor $\mathrm{C} 2 \mid \mathrm{C} 4$, and no RCPs.

Table 3. QTAIM charges and energies at $\operatorname{CCSD}($ full)/6-311+G(2d,p)(tight) and B3PW91/augcc-pVTZ(tight)

\begin{tabular}{cccc}
\hline Cation & Charge & $\mathrm{E}_{\text {elec }}(\Sigma \mathrm{E}(\Omega))$ & $\mathrm{E}_{\text {elec }}$ \\
\hline $\mathbf{1 - C} \boldsymbol{S}$ & $1.0003^{\mathrm{a}}$ & -155.973727 & -155.973458 \\
& $(0.9997)^{b}$ & $(-156.290405)$ & $(-156.290401)$ \\
$\mathbf{T S}-\mathbf{1} \rightarrow \mathbf{2}$ & $(1.0001)$ & $(-156.289480)$ & $(-156.289613)$ \\
& 1.0021 & -155.973847 & -155.973170 \\
$\mathbf{2}-\boldsymbol{C}_{\boldsymbol{S}}$ & $(1.0012)$ & $(-156.292354)$ & $(-156.291993)$ \\
& $(\mathbf{1 . 0 0 1 5})^{c}$ & $(-156.292467)^{a}$ & $(-156.291993)$ \\
$\mathbf{3}-\boldsymbol{C}_{\boldsymbol{S}}$ & 1.0005 & -195.227542 & -195.227514 \\
& $(1.0008)$ & $(-195.625037)$ & $(-195.624835)$ \\
\hline
\end{tabular}

${ }^{a}$ At $\operatorname{CCSD}\left(\right.$ full) $/ 6-311+\mathrm{G}(2 \mathrm{~d}, \mathrm{p})\left(\right.$ tight). ${ }^{\mathrm{b}}$ Values in italics in brakets at B3PW91/aug-ccpVTZ(tight). ${ }^{c}$ Values in bold italics in brackets at B3PW91/aug-cc-pVTZ(opt=verytight, int=ultrafine). 
(a)

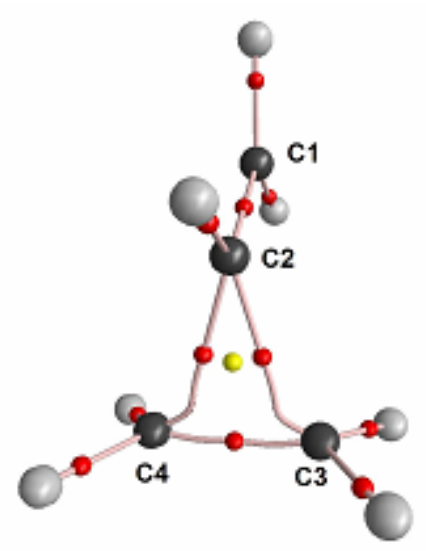

(b)

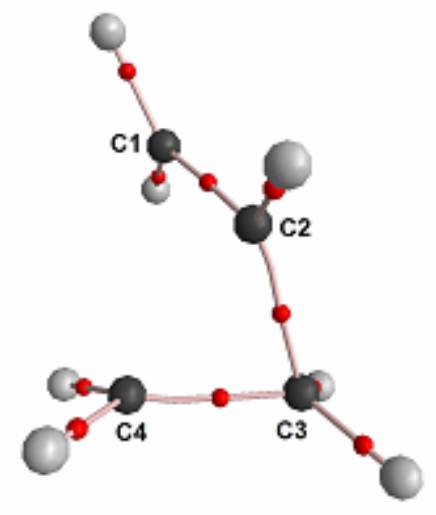

Figure 2. (a) molecular graph of $\mathbf{1}-\boldsymbol{C}_{\boldsymbol{S}}$ at $\mathrm{CCSD}(\mathrm{full}) / 6-311+\mathrm{G}(2 \mathrm{~d}, \mathrm{p})(\mathrm{tight})$, (b) $\mathbf{T S}-\mathbf{1} \rightarrow \mathbf{2}$ at B3PW91/aug-cc-pVTZ(tight). Black spheres are carbon atoms and grey spheres are hydrogens. The red spheres are $(3,-1)$ bond critical points $(\mathrm{BCPs})$ and the yellow sphere is the $(3,+1)$ ring critical point $(\mathrm{RCP})$.

The molecular graph of 2- $\boldsymbol{C}_{\boldsymbol{S}}$ obtained at $\operatorname{CCSD}($ full) $/ 6-311+\mathrm{G}(2 \mathrm{~d}, \mathrm{p})($ tight $)$ is displayed as Figure 3(a) and 3(b) with 3(b) clearly showing the puckered nature of the ring structure. The Poincaré-Hopf relationship is also satisfied in the case of $2-\boldsymbol{C}_{\boldsymbol{S}}$. The $\mathrm{C} 2-\mathrm{C} 3$ and $\mathrm{C} 3-\mathrm{C} 4$ bond paths (BPs) exhibit considerable curvature. The most important point is that $\mathbf{2}-\boldsymbol{C}_{\boldsymbol{S}}$ does not exhibit a BCP/BP between $C 1$ and $C 3$ at its equilibrium geometry at the CCSD(full)/6$311+G(2 d, p)$ level; $C 3$ is not a penta-coordinate carbon atom - it does not have five bond paths terminating at the nucleus. This is the case at the B3PW91/aug-cc-pVTZ(tight) level and B3PW91/aug-cc-pVTZ(opt=verytight, int=ultrafine) as well.

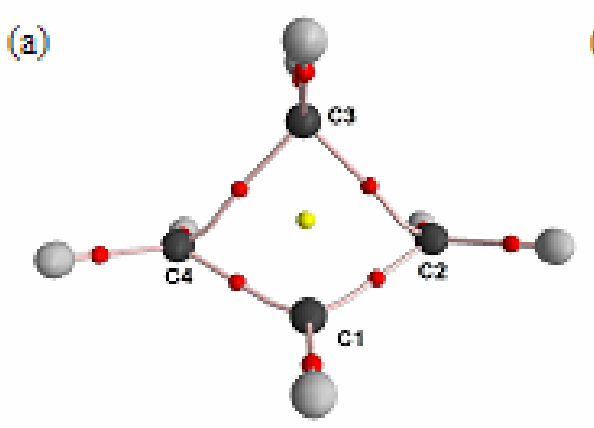

(b)

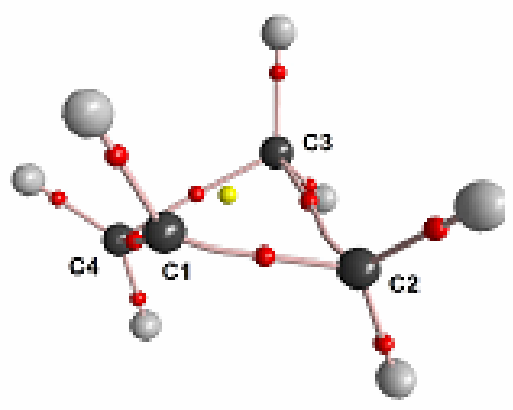

Figure 3. (a) molecular graph of $\mathbf{2}-\boldsymbol{C}_{\boldsymbol{S}}$ at $\operatorname{CCSD}(\mathrm{full}) / 6-311+\mathrm{G}(2 \mathrm{~d}, \mathrm{p})(\mathrm{tight})$ and (b) $\mathbf{2}-\boldsymbol{C}_{\boldsymbol{S}}$ at $\mathrm{CCSD}($ full $) / 6-311+\mathrm{G}(2 \mathrm{~d}, \mathrm{p})($ tight $)$ re-orientated.

The molecular graph of 3- $\boldsymbol{C}_{\boldsymbol{S}}$ obtained at $\operatorname{CCSD}(\mathrm{full}) / 6-311+\mathrm{G}(2 \mathrm{~d}, \mathrm{p})$ is displayed as Figure 4(a) with 4(b) showing the puckered nature of its ring structure. The Poincaré-Hopf relationship is satisfied. The C2-C3 and C3-C4 bond paths (BPs) don't exhibit the same degree of curvature 
as the corresponding BPs of $\mathbf{2}-\boldsymbol{C}_{S}$ indicating qualitatively that $\mathbf{3}-\boldsymbol{C}_{S}$ has a more stable molecular structure than $\mathbf{2}-\boldsymbol{C}_{\boldsymbol{S}}$. Once again the important point is that, like $\mathbf{2}-\boldsymbol{C}_{\boldsymbol{S}}, \mathbf{3}-\boldsymbol{C}_{\boldsymbol{S}}$ does not exhibit a $\mathrm{BCP} / \mathrm{BP}$ between $\mathrm{C} 1$ and $\mathrm{C} 3$ at its equilibrium geometry at the $\mathrm{CCSD}(\mathrm{full}) / 6-311+\mathrm{G}(2 \mathrm{~d}, \mathrm{p})$ level; C3 is not a penta-coordinate carbon atom. Like $\mathbf{2}-\boldsymbol{C}_{\boldsymbol{S}}$, this is also the case at the B3PW91/augcc-pVTZ(tight) level.

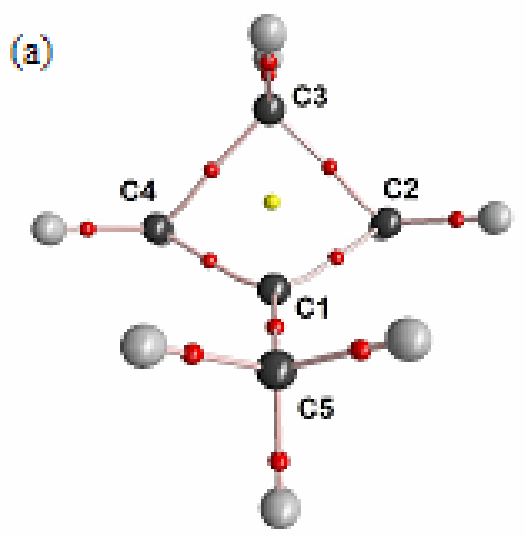

(b)

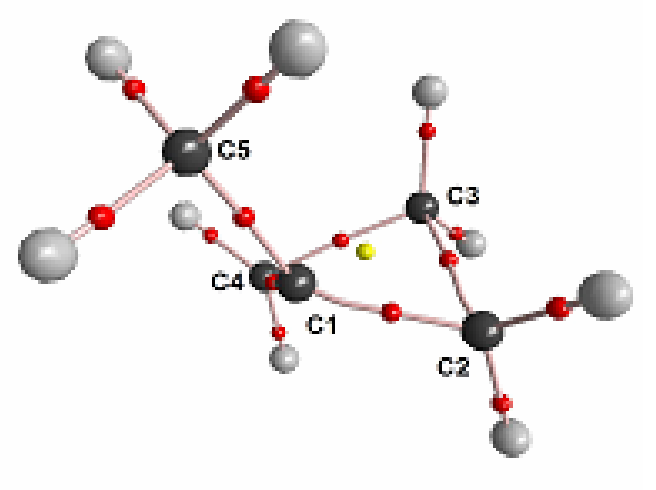

Figure 4. (a) molecular graph of $3-\boldsymbol{C}_{\boldsymbol{S}}$ at $\operatorname{CCSD}\left(\right.$ full) $/ 6-311+\mathrm{G}(2 \mathrm{~d}, \mathrm{p})\left(\right.$ tight), and (b) $\mathbf{3}-\boldsymbol{C}_{\boldsymbol{S}}$ at $\mathrm{CCSD}($ full $) / 6-311+\mathrm{G}(2 \mathrm{~d}, \mathrm{p})($ tight $)$ re-orientated.

\section{QTAIM-DI-VISAB Analyses}

$1-C_{S}$

Selected atomic basins of $1-C_{S}$ obtained at the $\operatorname{CCSD}($ full $) / 6-311+\mathrm{G}(2 \mathrm{~d}, \mathrm{p})($ tight $)$ level are displayed as Figure 5(a) and (b); Figure 5(a) shows that the $\mathrm{C} 1$ and $\mathrm{C} 3$ basins do not significantly impinge on each other in accord with the fact that they that exhibit a miniscule DI of 0.087: there is little delocalization of electrons between the $\mathrm{C} 1$ and $\mathrm{C} 3$ basins. As expected the DI (0.141) is somewhat larger at B3PW91/aug-cc-pVTZ. The C1-C2 bond exhibits considerable double bond character $-\rho(\mathbf{r})_{\mathrm{cp}}$ is 0.3435 and the DI 1.317. On the other hand the $\mathrm{C} 2-\mathrm{C} 3$ and $\mathrm{C} 2-\mathrm{C} 4$ bonds are very weak $-\rho(\mathbf{r})_{\mathrm{cp}}$ is 0.1656 and DI 0.590 at $\mathrm{CCSD}$ (full)/6$311+\mathrm{G}(2 \mathrm{~d}, \mathrm{p})$. The relative areas of the atomic surfaces shared with $\mathrm{C} 2$ seen in Figure 5(a) are in accord with the relative strengths of the $\mathrm{C} 1-\mathrm{C} 2$ and $\mathrm{C} 2-\mathrm{C} 3$ bonds. These values are proportionally larger (see Table 2 and Table 3) at B3PW91/aug-cc-pVTZ. Figure 5(b) shows the $\mathrm{C} 2$ basin illustrating its flattened surfaces shared with the $\mathrm{C} 3$ and $\mathrm{C} 4$ basins. The $\mathrm{C} 3 \mid \mathrm{C} 4$ basins exhibit a DI of 0.986, close to the DI expected for a single bond. 
Table 4. Selected delocalization indexes for pairs of atoms at $\operatorname{CCSD}($ full)/6-311+G(2d,p)(tight) and B3PW91/aug-cc-pVTZ(tight).

\begin{tabular}{|c|c|c|c|c|}
\hline $\begin{array}{l}\text { Atom Pairs } \\
\left(\Omega \text { and } \Omega^{\prime}\right)\end{array}$ & $1-C_{S}$ & TS-1 $\rightarrow 2$ & $2-C_{S}$ & $3-C_{S}$ \\
\hline $\mathrm{C} 1 \mid \mathrm{C} 2$ & $1.317^{\mathrm{a}}(1.572)^{\mathrm{b}}$ & 1.460 & $\begin{array}{c}0.965(1.147) \\
(\mathbf{1 . 1 4 7 )}\end{array}$ & $0.939(1.109)$ \\
\hline $\mathrm{C} 2 \mid \mathrm{C} 3$ & $0.590(0.715)$ & 0.934 & $\begin{array}{c}0.651(0.788) \\
(\boldsymbol{0 . 7 8 8})\end{array}$ & $0.689(0.839)$ \\
\hline $\mathrm{C} 1 \mid \mathrm{C} 3$ & $0.087(0.141)$ & 0.085 & $\begin{array}{c}0.443(0.558) \\
(\mathbf{0 . 5 5 7})\end{array}$ & $0.338(0.419)$ \\
\hline $\mathrm{C} 3 \mid \mathrm{C} 4$ & $0.986(1.164)$ & 1.051 & $-{ }^{c}$ & $-c$ \\
\hline $\mathrm{C} 1 \mid \mathrm{C} 4$ & $-\mathbf{c}$ & 0.329 & $-^{c}$ & $-^{c}$ \\
\hline $\mathrm{C} 2 \mid \mathrm{C} 4$ & $-c$ & 0.599 & $\begin{array}{c}0.066(0.096) \\
(\mathbf{0 . 0 9 6 )}\end{array}$ & $0.065(0.084)$ \\
\hline $\mathrm{C} 1 \mid \mathrm{C} 5$ & - & - & - & $0.886(1.053)$ \\
\hline
\end{tabular}

${ }^{a}$ At $\operatorname{CCSD}($ full $) / 6-311+\mathrm{G}(2 \mathrm{~d}, \mathrm{p})($ tight $){ }^{\mathrm{b}}$ Values in italics in brakets at B3PW91/aug-ccpVTZ(tight). ${ }^{b}$ Values in bold italics in brakets at B3PW91/aug-cc-pVTZ(opt-verytight), intultrafine). ${ }^{\mathrm{c}}$ Data for atom pairs related by symmetry not included.

(a)

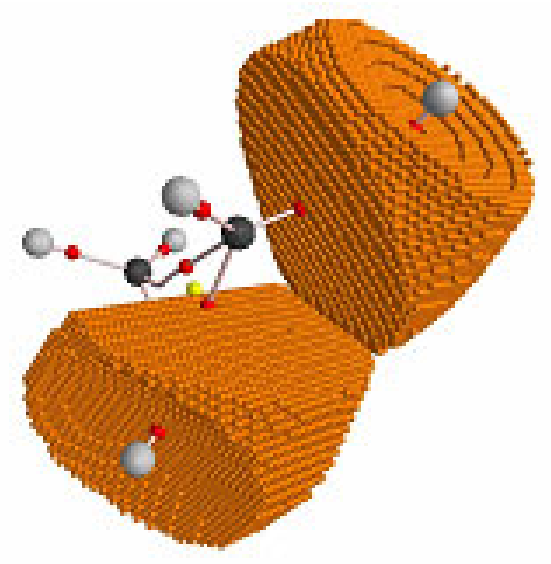

(b)

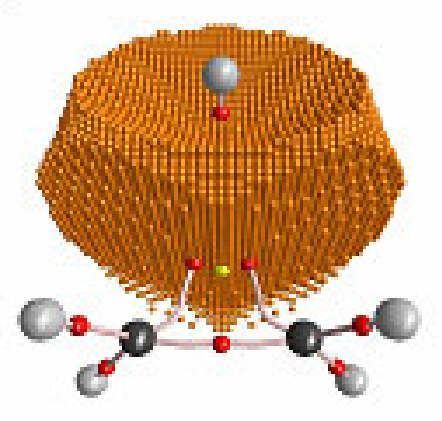

Figure 5. (a) $\mathrm{C} 1$ and $\mathrm{C} 3$ basins of $\mathbf{1 -} \boldsymbol{C}_{\boldsymbol{S}}$ at $\mathrm{CCSD}($ full)/6-311+G(2d,p)(tight), (b) $\mathrm{C} 2$ basin of 1$\boldsymbol{C}_{\boldsymbol{S}}$ at $\mathrm{CCSD}($ full $) / 6-311+\mathrm{G}(2 \mathrm{~d}, \mathrm{p})($ tight $)$.

TS-1 $\rightarrow$ 2

Figure 6(a) and (b) display the $\mathrm{C} 1 \mid \mathrm{C} 4$ and $\mathrm{C} 2 \mid \mathrm{C} 4$ basins of TS-1 $\rightarrow \mathbf{2}$. Even though there is no $\mathrm{BCPs} / \mathrm{BPs}$ between these pairs of basins, $\mathrm{C} 1$ and $\mathrm{C} 2$ are in close proximity to $\mathrm{C} 4$. Figure 6(c) shows how C4 is 'distorted' by the presence of C1 and C2. At B3PW91/aug-cc-pVTZ, the C1|C4 and $\mathrm{C} 2 \mid \mathrm{C} 4 \mathrm{DIs}$ are 0.329 and 0.599 indicating that the delocalization of electrons between $\mathrm{C} 2-\mathrm{C} 4$ 
is twice as large as it is in the case of C1-C4. Figure 6(d) shows the $\mathrm{C} 3$ basin that possesses a 'wedge' of density that intervenes between $\mathrm{C} 2$ and $\mathrm{C} 4$ and precludes the existence of a BCP/BP.

(a)

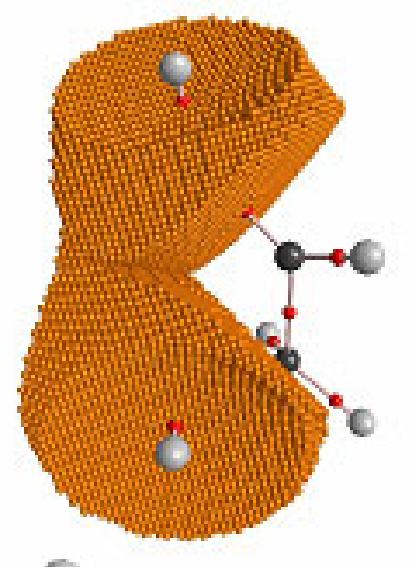

(c)

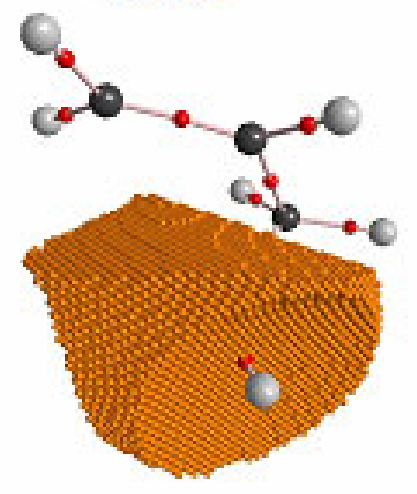

(b)

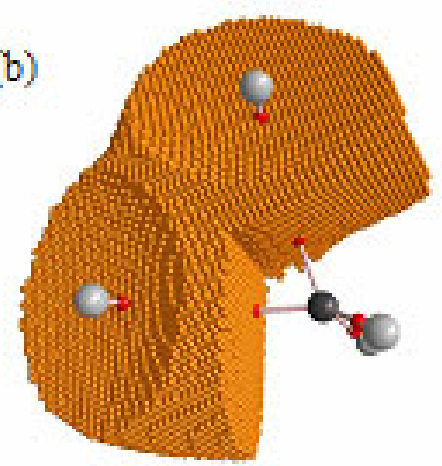

(d)

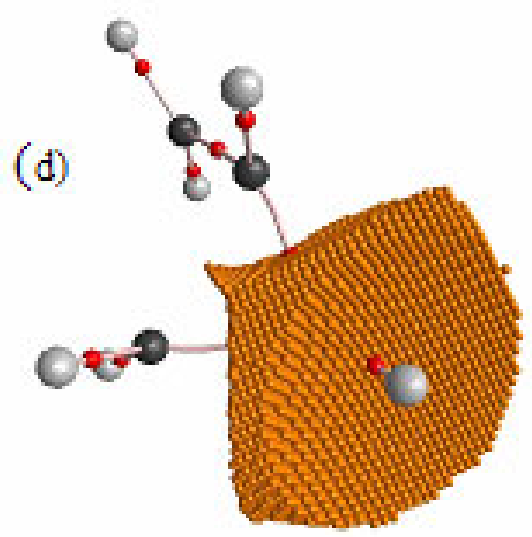

Figure 6. (a) $\mathrm{C} 1$ and $\mathrm{C} 4$ basins of TS-1 $\rightarrow \mathbf{2}$ at B3PW91/aug-cc-pVTZ(tight), (b) C2 and C4 basins of TS-1 $\rightarrow \mathbf{2}$ at B3PW91/aug-cc-pVTZ(tight), (c) C4 basin of TS-1 $\rightarrow \mathbf{2}$ at B3PW91/aug-ccpVTZ(tight), and (d) C3 basin of TS-1 $\rightarrow \mathbf{2}$ at B3PW91/aug-cc-pVTZ(tight).

Figure 7(a) shows the $\mathrm{C} 1 \mid \mathrm{C} 3$ basins of $2-C_{S}$ at $\mathrm{CCSD}($ full $) / 6-311+\mathrm{G}(2 \mathrm{~d}, \mathrm{p})($ tight $)$ that do not exhibit a BCP/BP. Nevertheless there is a high degree of delocalization of electrons between these basins; the DI is high at 0.443; 0.588 at B3PW91/aug-cc-pVTZ. Figure 7(b) and (c) display the $\mathrm{C} 1$ and $\mathrm{C} 3$ basins and clearly show the 'distortion' induced by their proximity. The DI for the $\mathrm{C} 2 \mid \mathrm{C} 4$ pair is 0.066 at $\mathrm{CCSD}$ (full)/6-311+G(2d,p)(tight) and 0.096 at B3PW91/aug-cc-pVTZ. We observed this behaviour - relatively large DIs but no BPs - previously for the so-called 7norbornyl cation ${ }^{13}$ and in the case of trimethylsilyl(carbene) and trimethylgermyl(carbene).$^{12}$ 


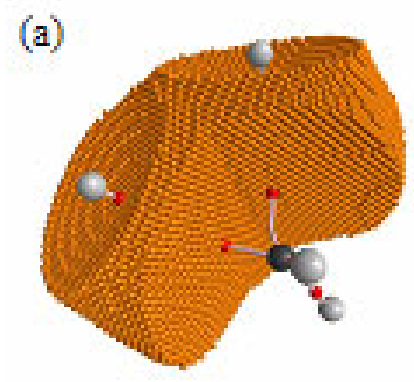

(b)

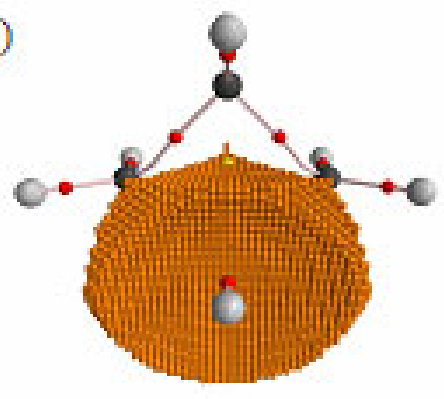

(c)

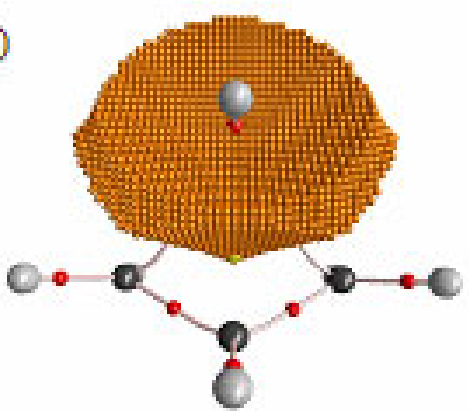

Figure 7. (a), $\mathrm{C} 1$ and $\mathrm{C} 3$ basins of $2-\boldsymbol{C}_{S}$ at $\mathrm{CCSD}(\mathrm{full}) / 6-311+\mathrm{G}(2 \mathrm{~d}, \mathrm{p})($ tight), (b) $\mathrm{C} 1$ basin of 2$C_{S},(\mathrm{c}) \mathrm{C} 3$ basin of $\mathbf{2}-\boldsymbol{C}_{\boldsymbol{S}}$.

Figure 8(a) shows the $\mathrm{C} 1 \mid \mathrm{C} 3$ basins of 3- $\boldsymbol{C}_{S}$ at $\mathrm{CCSD}$ (full)/6-311+G(2d,p)(tight) that do not exhibit a $\mathrm{BCP} / \mathrm{BP}$. As seen in the case of $\mathbf{2}-\boldsymbol{C}_{\boldsymbol{S}}$ there is a high degree of delocalization of electrons between these basins; the DI is quite large (0.338) but smaller than in the case of $\mathbf{2}-\boldsymbol{C}_{\boldsymbol{S}}$; at B3PW91/aug-cc-pVTZ the value is 0.419. Figure 7(b) and (c) display the $\mathrm{C} 1$ and $\mathrm{C} 3$ basins that clearly show how they impinge on each other their surfaces are flattened. The DI for the C2|C4 pair is 0.065 at $\operatorname{CCSD(full)/6-311+G(2d,p)(tight)~and~0.084~at~B3PW91/aug-cc-pVTZ.~}$
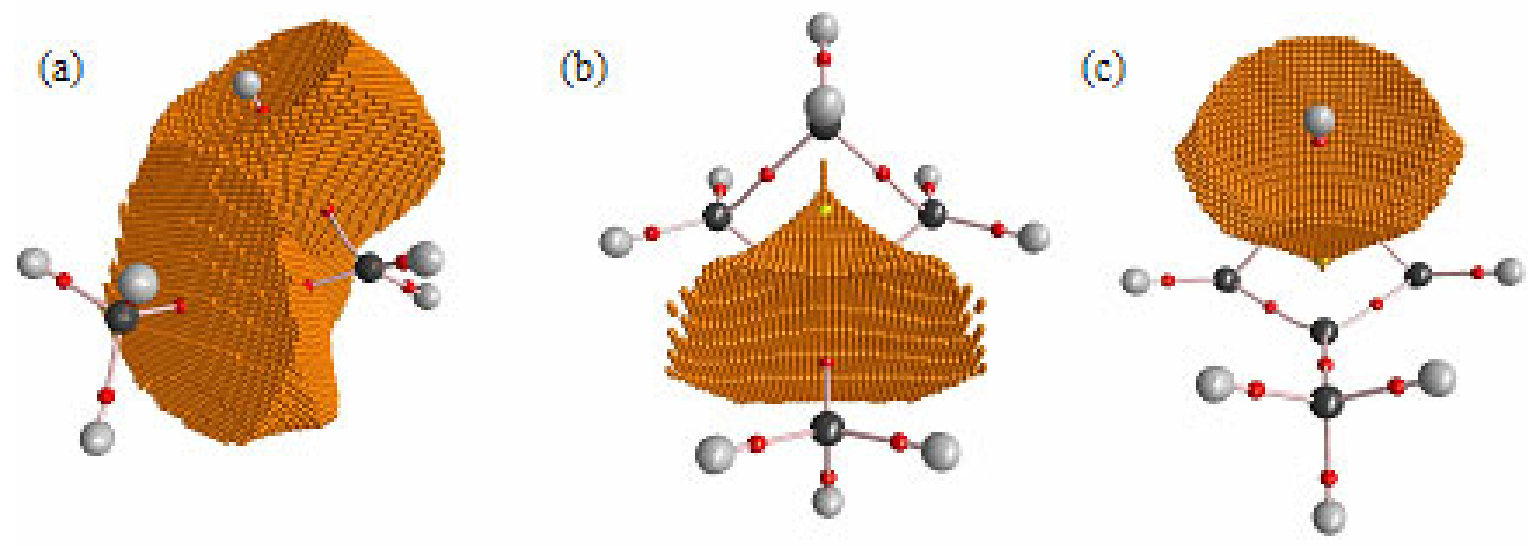

Figure 8. (a) $\mathrm{C} 1$ and $\mathrm{C} 3$ basins of $3-C_{S}$ at $\operatorname{CCSD}($ full) $/ 6-311+\mathrm{G}(2 \mathrm{~d}, \mathrm{p})($ tight), (b) $\mathrm{C} 1$ basin of 3$\boldsymbol{C}_{\boldsymbol{S}}$, (c) C3 basin of $\mathbf{3}-\boldsymbol{C}_{\boldsymbol{S}}$.

\section{Conclusions}

This study shows that the so-called nonclassical bicyclobutonium cation exhibits the molecular structure/graph of a distorted cyclobutyl cation at its equilibrium geometry. It documents another successful application of the QTAIM-DI-VISAB method in establishing the true nature of the bonding in hyper-coordinated so-called nonclassical carbocations; this approach obviates the 
need for using arbitrary dotted-line or solid-line representations of bonding in hypercoordinate species.

\section{Acknowledgements}

Financial support by the Natural Sciences and Engineering Research Council of Canada (NSERC) is gratefully acknowledged. Computing resources of the McMaster node of SHARCnet (Shared Hierarchical Academic Research Computing Network (of Ontario)) were used in this study.

\section{References}

1. Olah, G. A.; Prakash, G. K. S.; Rasul, G. J. Am. Chem. Soc. 2008, 130, 9168.

2. Dewar, M. J. S.; Reynolds, C. H. J. Am. Chem. Soc. 1984, 106, 6388.

3. Koch, W.; Liu, B.; DeFrees, D. J. J. Am. Chem. Soc. 1988, 110, 7325.

4. Casanova, J.; Kent, D. R.; Goddard, W. A.; Roberts, J. D. Proc. Natl. Acad. Sci. 2003, 100, 15.

5. Brown, H. C. The Nonclassical Ion Problem, with comments by Schleyer, P. v. R. Plenum: New York, NY, 1977, Ch. 5.

6. Bader, R. F. W. Atoms in Molecules - A Quantum Theory. Oxford University Press: Oxford, UK. 1990.

7. Werstiuk, N. H.; Muchall, H. M. J. Mol. Struct (Theochem). 1999, 463, 225.

8. Werstiuk, N. H.; Muchall, H. J. Phys. Chem. A. 1999, 103, 6599.

9. Werstiuk, N. H.; Muchall, H. J. Phys. Chem. A. 2000, 104, 2054.

10. Werstiuk, H. H.; Muchall, H. M.; Noury, S. J. Phys. Chem. A. 2000, 104, 11601.

11. Bajorek, T.; Werstiuk, N. H. Can. J. Chem. 2005, 83, 1352.

12. Poulsen, D. A.; Werstiuk, N. H. J. Chem. Theory. Comput. 2006, 2, 77.

13. Werstiuk, N. H. J. Chem. Theory. Comput. 2007, 3, 2258.

14. Werstiuk, N. H.; Sokol, W. Can. J. Chem. 2008, 86, 737.

15. Carlier, P. R.; Deora, N.; Crawford, T. D. J. Org. Chem. 2005, 71, 1592.

16. Frisch, M. J.; Trucks, G. W.; Schlegel, H. B.; Scuseria, G. E.; Robb, M. A.; Cheeseman, J. R.; Montgomery, Jr., J. A.; Vreven, T.; Kudin, K. N.; Burant, J. C.; Millam, J. M.; Iyengar, S. S.; Tomasi, J.; Barone, V.; Mennucci, B.; Cossi, M.; Scalmani, G.; Rega, N.; Petersson, G. A.; Nakatsuji, H.; Hada, M.; Ehara, M.; Toyota, K.; Fukuda, R.; Hasegawa, J.; Ishida, M.; Nakajima, T.; Honda, Y.; Kitao, O.; Nakai, H.; Klene, M.; Li, X.; Knox, J. E.; Hratchian, H. P.; Cross, J. B.; Bakken, V.; Adamo, C.; Jaramillo, J.; Gomperts, R.; Stratmann, R. E.; Yazyev, O.; Austin, A. J.; Cammi, R.; Pomelli, C.; Ochterski, J. W.; Ayala, P. Y.; Morokuma, K.; Voth, G. A.; Salvador, P.; Dannenberg, J. J.; Zakrzewski, V. G.; Dapprich, 
S.; Daniels, A. D.; Strain, M. C.; Farkas, O.; Malick, D. K.; Rabuck, A. D.; Raghavachari, K.; Foresman, J. B.; Ortiz, J. V.; Cui, Q.; Baboul, A. G.; Clifford, S.; Cioslowski, J.; Stefanov, B. B.; Liu, G.; Liashenko, A.; Piskorz, P.; Komaromi, I.; Martin, R. L.; Fox, D. J.; Keith, T.; Al-Laham, M. A.; Peng, C. Y.; Nanayakkara, A.; Challacombe, M.; Gill, P. M. W.; Johnson, B.; Chen, W.; Wong, M. W.; Gonzalez, C.; Pople, J. A. Gaussian 03, Revision B.02 and C.02, Gaussian, Inc., Wallingford CT, 2004.

17. Cremer, D.; Svensson, P.; Kraka, E.; Ahlberg, P. J. Am. Chem. Soc. 1993, 115, 7445.

18. ChemCraft. Version 1.5. http://www.chemcraftprog.com.

19. Biegler-Konig, F. AIM 2000 [computer program]. Copyright (C) 1998-2000, University of Applied Science, Bielefeld, Germany.

20. Keith, T. A. AIMALL (Version 08.04.21) for WINDOWS; aim@tkgristmill.com.

21. Wang, Y.-G.; Werstiuk, N. H. J. Comput. Chem. 2003, 24, 379.

22. Wang, Y.-G.; Matta, C.; Werstiuk, N. H. J. Comput. Chem. 2003, 24, 1720.

23. Wang, Y-G.; Wiberg, K. B.; Werstiuk, N. H. J. Phys. Chem. A. 2007, 111, 3592. 